\title{
The role of seed testing
}

\author{
D. J. ScotT \\ MAF Seed Testing Station, Palmerston North
}

ABSTRACT. An account is given of the place of seed testing in New Zealand agriculture. The functions of the Government Seed Testing Station are outlined, including sections on the role of testing in the Government seed certification scheme, testing seed for export, seed importation. noxious plants Rhizobium testing, surveys and research. Also discussed are the procedures and aspects of seed quality testing relevant to New Zealand pasture seeds, in cluding sampling, purity, germination, seed health. seed vigour, cultivar and tolerances.

Key words: Seed testing, New Zealand, noxious plants, Rhizobium.

\section{INTRODUCTION}

A Government seed testing service has existed in New Zealand since early this century and can claim to have played an essential part in the development of this country's agriculture during the intervening years. In 1911, Lonsdale ( 191 1) commented that "to the agriculturalist pure seed of good vitality is of the utmost importance yet it is remarkable that very little attention is paid to quality, quantity being too often considered of greater importance." Cockayne ( 1913) observed that "agricultural seeds probably vary more in quality and, therefore, in value than any other commodity the farmer has to buy". It is still widely recognized that one of the great hazards in agriculture is sowing seed that will not grow, or is contaminated with seeds of unwanted or noxious plants, or is carrying harmful plant diseases.

Many countries regard seed to be such an important agricultural input that legislation has been enacted to ensure that any seed offered for sale reaches minimum standards of quality. New Zealand is one of the few coun- tries that does not have such legal standards. Instead, it operates an approach to control that is based on the concept of educating users to buy high-quality, Government-certified agricultural seed. The success of this voluntary approach is evidenced by the fact that a large proportion, estimated to be over $80 \%$, of the agricultural seed purchased by seed merchants from growers, traded in the wholesale markets or retailed, is priced and traded on the basis of certificates of analysis issued by the Official Seed Testing Station. The use of official analysis certificates is also essential for export of seeds to most overseas markets.

\section{FUNCTIONS OF THE GOVERNMENT SEED TESTING STATION}

The primary functions of the Seed Testing Station are to provide the New Zealand seed industry with a prompt and efficient seed quality testing service, and to encourage the use of high-quality, tested seed by the farming industry. Analysis certificates giving an assessment of seed quality are used by the seed industry as an instrument of trading in a market which is highly speculative and subject to

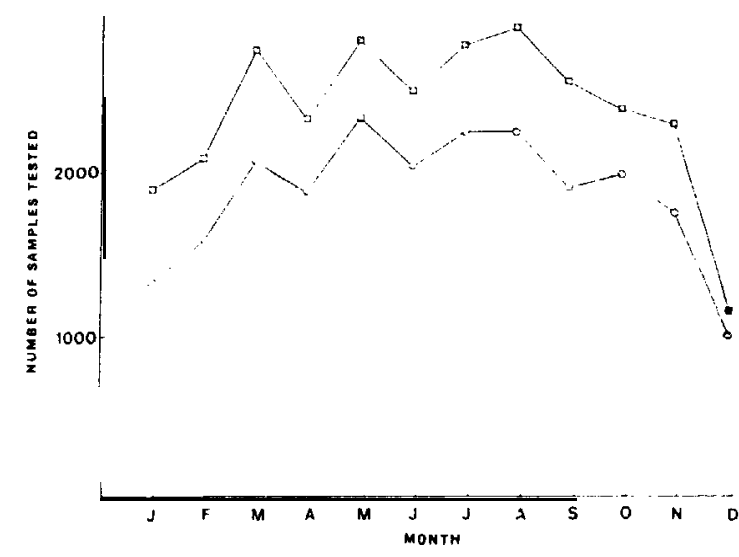

FIG. 1: Average number of purity (circles) and germination (squares) tests curried out per, month at the Seed Testing Station. 1973-778. 
rapid fluctuations in supply and demand. Except for the December-lanuary period, a reasonably even flow of seed samples is received at the station during the year (Fig. 1), and this occurs as a consequence of seed stores spreading their work to obtain full utilization of seed-cleaning facilities.

Role of Testing in the Government SeED Certification Scheme

Seed quality testing plays an important role in the Government seed certification scheme. Certified seed which has been field inspected during the growing season, and supervised dur- ing machine cleaning, must be finally tested for purity and germination. Purity standards must be met (Table 1) and seed samples must be free of wild oat (Avena fatua L.) and nodding thistle (Carduus nutans L.) contamination before final certification is approved.

The lack of germination standards for certified seed is often regarded as a weakness of the certification scheme, since many farmers believe that certified seed is high-quality seed in every respect. However, it would be difficult to set realistic standards which could take account of the inevitable decline in germina-

TABLE 1: PURITY STANDARDS FOR GOVERNMENT-CERTIFIED HERBAGE SEEDS

\begin{tabular}{|c|c|c|c|c|}
\hline Kind of Seed & Class & $\begin{array}{l}\text { Min. Pure } \\
\text { Seeds \% }\end{array}$ & $\begin{array}{l}\text { Max. Other } \\
\text { Crop Seeds \% }\end{array}$ & $\begin{array}{c}\text { Max. Weed } \\
\text { Seeds \% }\end{array}$ \\
\hline \multicolumn{5}{|l|}{ Grasses } \\
\hline Crested dogstail & $\begin{array}{l}\text { basic } \\
\text { first and second } \\
\text { generation }\end{array}$ & $\begin{array}{l}99.5 \\
96.0\end{array}$ & $\begin{array}{l}0.3 \\
2.0\end{array}$ & $\begin{array}{l}0.2 \\
1.0\end{array}$ \\
\hline Cocksfoot & $\begin{array}{l}\text { basic } \\
\text { first and second } \\
\text { generation }\end{array}$ & $\begin{array}{l}85.0 \\
80.0\end{array}$ & $\begin{array}{l}0.3^{1} \\
3.0\end{array}$ & $\begin{array}{c}0.2 \\
1.0\end{array}$ \\
\hline Prairie grass & $\begin{array}{l}\text { basic } \\
\text { first generation } \\
\text { second generation }\end{array}$ & $\begin{array}{l}98.0 \\
98.0 \\
96.0\end{array}$ & $\begin{array}{l}0.3 \\
0.5 \\
1.0\end{array}$ & $\begin{array}{l}0.2 \\
0.5 \\
1.0\end{array}$ \\
\hline Ryegrass & $\begin{array}{l}\text { basic } \\
\text { first generation } \\
\text { second generation } \\
\text { and permanent pasture }\end{array}$ & $\begin{array}{l}99.5 \\
98.0 \\
97.0\end{array}$ & $\begin{array}{l}0.3 \\
1.0 \\
1.0\end{array}$ & $\begin{array}{l}0.2 \\
0.5 \\
1.0\end{array}$ \\
\hline Timothy & $\begin{array}{l}\text { basic } \\
\text { first and } \\
\text { second generation }\end{array}$ & $\begin{array}{l}99.5 \\
98.0\end{array}$ & $\begin{array}{l}0.3 \\
1.0\end{array}$ & $\begin{array}{l}0.2 \\
0.5\end{array}$ \\
\hline \multicolumn{5}{|l|}{ Legumes } \\
\hline Lotus spp. & $\begin{array}{l}\text { basic } \\
\text { first generation } \\
\text { second generation }\end{array}$ & $\begin{array}{l}99.0 \\
97.0 \\
93.0\end{array}$ & $\begin{array}{l}0.3 \\
0.5^{2} \\
1.0^{2}\end{array}$ & $\begin{array}{c}0.2 \\
0.5 \\
1.0\end{array}$ \\
\hline Lucerne & $\begin{array}{l}\text { basic and } \\
\text { first generation } \\
\text { second generation }\end{array}$ & $\begin{array}{l}98.0 \\
98.0\end{array}$ & $\begin{array}{l}1.0^{3} \\
\text { I. } 0\end{array}$ & $\begin{array}{l}0.5 \\
0.5\end{array}$ \\
\hline Red clover & $\begin{array}{l}\text { basic } \\
\text { first and second } \\
\text { generation }\end{array}$ & $\begin{array}{l}99.5 \\
98.0\end{array}$ & $\begin{array}{l}0.3 \\
0.5\end{array}$ & $\begin{array}{l}0.2 \\
C .5\end{array}$ \\
\hline White clover & $\begin{array}{l}\text { basic } \\
\text { first generation } \\
\text { second generation } \\
\text { and permanent pasture }\end{array}$ & $\begin{array}{l}99.0 \\
97.0 \\
93.0\end{array}$ & $\begin{array}{l}0.3^{\prime} \\
0.5^{\prime} \\
1.0^{4}\end{array}$ & $\begin{array}{l}0.2 \\
0.5 \\
1.0\end{array}$ \\
\hline
\end{tabular}

\footnotetext{
1 Max. trace \% ryegrass in working sample.

2 Other than white and suckling clover.

'Max. $0.5 \%$ red clover.

4 Other than suckling clover.
} 
tion after testing is carried out. For this reason buyers arc encouraged to examine all certificates for details of purity and germination, and date of issue, before making a purchase.

\section{Testing Seed for EXPort}

Approximately $45 \%$ of herbage seed produced in New Zealand is exported to a number of different markets, particularly the European Economic Community (EEC) , Australia and North and South America. Since most herbage seed lots are eligible for export, all tests are carried out in strict accordance with the international rules for seed testing (ISTA, 1976) even though the results are usually first issued on New Zealand certificates of analysis. Jnternational certificates may be subsequently issued based on test information originally reported on New Zealand certificates, without the need for further testing to be carried out. For this reason testing of herbage seed for domestic use is closely tied to testing for export.

Overseas trade in seeds is increasingly based on the use of international analysis (orange) certificates. New Zealand is a member of the Jnternational Seed Testing Association (ISTA), an organization that retains the sole right to authorize member stations to issue orange certificates. The Association's objects are to develop, adopt and publish all matters connected with accurate and uniform methods of testing and to actively promote evaluating seeds, in order to bring about efficiency in production, processing, distribution and utilization of seeds to be used for sowing.

\section{SEED I M PORTATION}

All lots of agricultural seed imported into New Zealand must be accompanied by various certificates including a certificate of analysis showing freedom from seeds of prohibited noxious plants. If seed arrives without such documentation a sample is taken from the seed lot on arrival and tested at the Seed Testing Station. If prohibited seeds are found the importer is required to reclean, reship or destroy the seed Jot concerned. In some instances tests for the presence of seed-borne diseases are also carried out, particularly when plant health documentation from overseas is inadequate.

\section{Noxious Plants}

The Seed Testing Station is in a unique position to be able to exert some control over the spread of noxious plants. When seeds of particularly serious noxious plants are found in New Zealand seed, steps are taken quickly to ensure that the seed is not sold or sown. A recent case occurred when seeds of a harmful species of dodder (Cuscuta spp.) were found in a commercial seed lot of lucerne. If wild oat or nodding thistle is detected in Governmentcertified seed samples, the seed lots concerned are rejected from certification. Contamination of seed lots with seed of any one of 13 undesirable noxious weed species (Table 2) is given special prominence on seed analysis certificates by showing both botanical and common names. In the past a seed lot initially found to be contaminated with one or more of these weed species could be officially retested in the hope that they would not be found again, and thus not reported on a new certificate. A recent change has been introduced to ensure that in such cases the occurrence of any of these species on a previous test certificate is automatically noted on all further retest crrtificates.

The important message for seed producers is that every effort should be made to effectively control weed infestation, particularly those weed species shown in Table 2. The penalty for not doing so is possible rejection of seed from ccrtification, or recording of species on

TABLE 2: UNDESIRABLE WEED SPECIES SHOWN ON SEED ANALYSIS CERTIFICATES WITH BOTH BOTANICAL AND COMMON NAMES

\begin{tabular}{ll}
\hline Botanical Name & Common Name \\
\hline A vena fatua L. & wild oat \\
Cardaria draba Desf. & hoary cress \\
Cardus nutans L. & nodding thistle \\
Carduus tenuiflorus Curt. & winged thistle \\
Chrysanthemum leucanthemum L. ox-eye daisy \\
Cirsium arvense Scop. & Californian thistle \\
Cirsium vulgare Ten. & Scotch thistle \\
Conium maculatum L. & hemlock \\
Convolvulus arvensis L. & field bindweed \\
Cuscuta spp. & dodder \\
Hordeum murinum L. & barley grass \\
Nassella trichotoma Hack. & nassella tussock \\
Senecio jacobea L. & ragwort \\
\hline
\end{tabular}


analysis certificates that can markedly reduce the value of the seed concerned.

\section{RHIZOBIUM TESTING}

In the past year the Seed Testing Station has taken on responsibility for testing commercially available Rhizobium inoculants and coated inoculated seed, particularly for pasture legume species and lucerne. The new service provides manufacturers with recommended strains of Rhizobium, sets numerical standards, nominates maximum expiry date, and tests each batch of inoculant for purity, strain identity and number of rhizobia. Coated inoculated seed is also laboratory tested to ensure that 300 viable rhizobia per seed are present after 28 days' storage at $20^{\circ} \mathrm{C}$. Random samples are field tested for establishment comparisons with standard laboratory coated seed.

The results of all tests are supplied to manufacturers and a list of products meeting the approved standards is published each year. This testing service is expected to benefit farmers by ensuring that onlv the most effective inoculants are on the market.

\section{SURVEYS}

In its day-to-day examination of samples, considerable statistical information is recorded for each of over 30000 samples analysed each year. At present the information can only be extracted by laboriously checking each test record, but the future use of compisters should greatly improve this situation. Some statistical information on seed quality is taken out on a routine basis, such as monthly germination summaries. There have also been instances when it has been necessary to obtain information from seed testing records about the occurrence of certain noxious impurities in seed lots. The data in Table 3 offer a further example.

\section{RESEARCH}

The Seed Testing Station has a small research staff of four scientists and two technicians. Much of the group's work is to undertake specialized analytical work, such as seed health testing and Rhizobium testing, but they are also required to carry out research work and to ensure that the best possible methods are used to assess the quality of seed.

Research staff are closely involved in investigations into some special problems concerning seed production or usage in New Zealand. In the herbage seed area, for example, investigations have confirmed the value of using nitrogen fertilizers in the spring to reduce the amount of blind seed disease (Gloeotinia temu. lenta Prill and Declacr.) infection in ryegrass seed crops (Hampton and Scott, 1980). Research has also been carried out into germination losses in crested dogstail (Cynosurus cristatus L.) seed during storage and shipment. and seed health problems associated with the production of seed of new cultivars of paspalum (Paspalum dilatatum Poir) and prairie grass (Bromus willdenowii Kunth.). The low temperature germination response of Lotus pedunculatus Cav. has also been investigated.

\section{SEED QUALITY TESTJNG}

In all cases the basic aim of seed testing is to determine the value of seed for planting (ISTA, 1976). Seed testing begins with sampling and subsequently involves a number of different laboratory procedures.

\section{SAM PLI NG}

The object of sampling is to obtain a sample of a size suitable for tests, in which the same constituents are present as in the seed lot, and in the same proportions (ISTA, 1976).

Official sampling of herbage seed is carried out in accordance with the rules of the International Seed Testing Association. All seed lots that are sampled must be identified with an officially recognized reference number, which is printed on the label attached to each bag. The same number appears on the certificate of analysis, thus establishing a connection between it and the seed lot. The maximum lot size for most herbage seed is 10 tonnes. In most cases a standard sampling trier is used and a specified number of bags in a seed lot are required to be sampled.

If there is evidence of lack of uniformity (heterogeneity) between bags in a seed lot, a sampling officer may refuse sampling. Although 
some degree of heterogeneity is unavoidable, many seed-cleaning operators aggravate the situation by making major adjustments to machinery during cleaning or by failing to distinguish properly between "firsts" and "seconds" of a line. Heterogeneity is the most common reason why retest results differ from results of earlier tests, a problem which may cause seed merchants considerable embarrassment.

\section{Purity Testing}

The object of a purity analysis is to determine the composition by weight of the sample being tested, and by inference the composition of the seed lot and the identity of the various species of seeds and inert particles in the sample (!STA, 1976).

The purity test involves an examination of a working sample that is approximately one-tenth the size of the submitted sample. Each working sample is divided into "pure seeds", "other seeds" and "inert matter". For New Zealand tests the other seeds may be further separated into "other crop seeds" and "weed seeds" categories. Each separation is weighed and expressed as a percentage of the whole working sample weight to give percent pure seed, other crop seed, weed seed and inert matter.

The balance of the submitted sample is examined for other contaminant species not found in the purity test, and their identity is disclosed in the "bulk search" section of a New Zenland certificate. This test is not carried out routinely in many other countries and is not required for an international analysis certificate unless specially requested. However, it is an integral part of the New Zealand seed-testing procedures and gives buyers a more accurate indication of the different species that are present in a seed lot at a low rate of occurrence.

\section{Germination testing}

Germination in a laboratory test is regarded as the emergence and development from the seed embryo of those essential structures which for the kind of seed being tested indicates its ability to develop into a normal plant under favourable conditions in the soil. The usual technique is to place four replicates of 100 pure seeds on damp blotting paper in a germination cabinet at the most suitable temperature for rapid germination. Germination counts are made after specified incubation periods, depending on the species. For example, with cocksfoot (Dactylis glomerata L.) a first count of normal seedlings is made after 7 days, and a final count of normal seedlings, abnormal seedlings and dead seeds is made after 21 days. White clover counts are made after 3 and 7 days. For legume seeds an additional assessment of hard seeds is made at the final count.

With some types of seeds, especially many grass seeds tested soon after harvest, special treatments, such as prechilling for 4 days at $5^{\circ} \mathrm{C}$ or the use of blotters soaked in potassium nitrate, must be used to overcome any postharvest dormancy that is present. The use of such treatments is shown on certificates, but the level of post-harvest dormancy is not routinely reported because it usually disappears before sowing.

Although doubts have often been expressed about the relevance of germination testing to practical sowing conditions, experience has shown that present techniques are generally the most reliable way of assessing the planting value of seed lots. Certificates should always be checked to ensure that germination results shown are from a fairly recent test.

\section{Seed Health Testing}

A number of diseases affect pasture seed production or are readily transmitted by seed. Seed health testing at the station is not normally carried out on samples of pasture seed, except where a definite need has been established.

Until 1974, samples of ryegrass seed, collected before harvest, were examined at the station for the presence of blind-seed disease infection. When crops were found to be severely infected they could be made into hay, thus avoiding harvesting and cleaning costs for a product that was practically worthless. This service was discontinued mainly because the use of the senvice by seed producers had declined markedly in the late 1960s and early 1970s (Scott, 1974). 
Other seed-borne diseases of pastures have been subject to periodic surveys (McKenzie, 1978; Matthews, 1971), but it has not been considered necessary to institute any routine seed health testing. However, there are some serious seed-borne diseases associated with seed production of new cultivars of prairie grass and paspalum (Lancashire et al., 1980) which may in future require control through routine seed health testing and the seed certification scheme.

\section{Seed Vigour testing}

Seed vigour refers to those properties of seed which influence the speed and uniformity of germination and the ability to germinate and emerge under a wide range of field conditions. Lack of seed vigour may be seen as slow or uneven field emergence, or failure to establish as well as laboratory germination tests otherwise indicate; effects which may lead to reduced crop yields. These effects may be further modified by sowing conditions, such as soil type, soil temperature and the availability of soil moisture (Perry, 1972). Differences in ability to retain germination during storage may also be attributed to differences in seed vigour (Delouche and Baskin, 1973).

Several types of laboratory test have been developed for seed vigour determination, particularly for large-seeded crop species such as peas and beans. No single test satisfied all requirements, and a method or combination of methods may be chosen to suit the species or cultivar concerned and the environment into which the seed is likely to be sown. In practice, seed vigour tests having a wide applica- tion have been very difficult to develop and few are yet in routine use.

There are indications that prairie grass seed taken from second or third harvests in the same season may be more prone to germination decline under storage conditions than seed taken from the first harvest. Similarly low vigour seed lots of crested dogstail arc prone to rapid germination decline during shipment to overseas markets, and a vigour test method to identify them is in the final stages of development at the Seed Testing Station.

The influence of seed weight of tetraploid 'Grasslands Tama' Westerwolds ryegrass (Lolium multiflorum Lam.) on subsequent plant performance has recently been recognized in New Zealand (Brown, 1977). This is an example of how differences in seed vigour between individual seeds or between seed lots, as measured by differences in seed weight, are reflected in differences in subsequent performance. These findings suggest that some account should be taken of seed weight in seed certification standards. However, with the wide range of seed weights that now exist (Table 3 ), a high level of rejection would occur. For cxample, a thousand seed weight standard of $4.0 \mathrm{~g}$ for 'Grasslands Tama' ryegrass would result in a rejection rate of approximately $25 \%$ of seed lots that would otherwise be eligible for certification.

It is of interest that for many years some seed merchants have voluntarily taken account of bushel weight in their transactions because they have observed positive relationshios between bushel weight and aspects of seed vigour such as keeping ability. For example, ryegrass

TABLE 3: A SURVEY OF THOUSAND SEED WEIGHT AND BUSHEL WEIGHT OF COMMERCIAI. S EE D L O T S OF GRASSLANDS-BREDRYEGRASS CUITIVARS

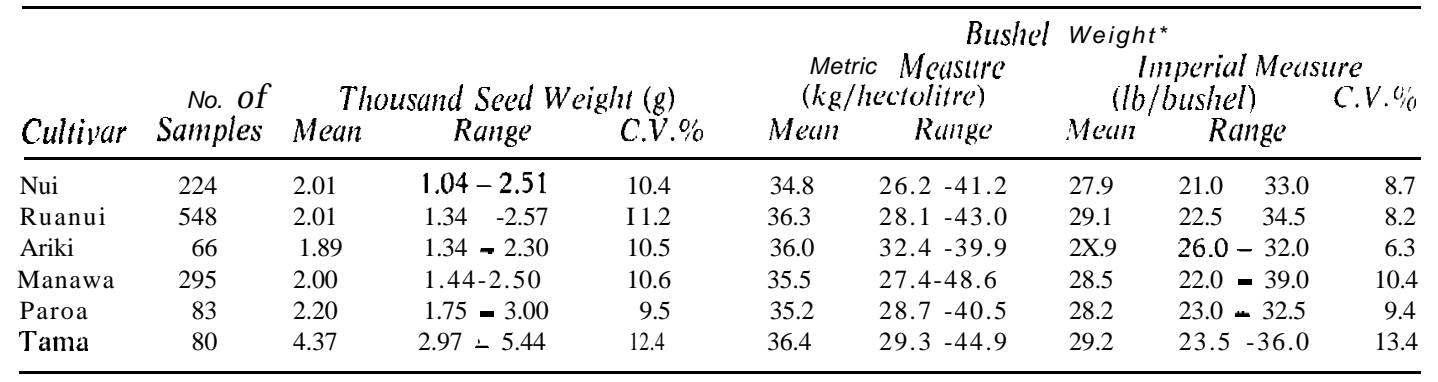

*Bushel weight data were obtained from every fifth sample. 
seed with a bushel weight of $28 \mathrm{lb}(35 \mathrm{~kg} /$ hectolitre) or more is generally preferred. The bushel weight data in Table 3 indicate a wide range of bushel weights in New Zealandproduced ryegrass seed, suggesting the need for a detailed appraisal of the significance of this seed characteristic.

Some of the many causes of low seed vigour (Heydecker, 1969) may be controlled by providing the best possible conditions for growth of the parent crop and proper handling and storage facilities for harvested seed. Unfortunately, some important causes such as drought stress or unsuitable harvest conditions are difficult or impossible to avoid.

\section{VARIETAL TESTING}

It is not common for laboratory tests to be able to distinguish between different varieties or cultivars of the same species. Two varietal tests for herbage seed are routinely used at the station. All samples of government-certified 'Grasslands Ruanui', 'Grasslands Nui', and permanent (PP) perennial ryegrass (Lolium perenne L.) are examined using an ultraviolet light test. Roots of short-lived varieties produce a fluorescent substance which glows under an ultraviolet light. True perennial ryegrass does not do this and any contamination present is easily detected. For government-certified basic perennial ryegrass seed no more than $1 \%$ fluorescence is permitted, for first generation $2 \%$, and for second generation $4 \%$. If these levels are exceeded the seed is downgraded or rejected from certification.

The picric acid test for white clover (Trifolium repens L.) depends on the fact that in New Zealand better varieties of white clove1 contain higher levels of cyanogenetic glucosides than do poorer strains (Foy and Hyde, 1937). The intensity of the colour change in a picric acid test is used to classify seed as government-certified permanent pasture (PP) white clover. In recent years very little PP white clover seed produced has been rejected on account of low cyanogenetic glucoside levels. This is undoubtedly due to the introduction of 'Grasslands Huia' white clover, which has a high glucoside content, into most New Zealand white clover seed producing areas.

\section{TOLERANCES}

Any test result is only an estimate of the quality of the seed lot as a whole and indicates that the true quality is likely to fall within certain limits on one side or other of the value obtained. For this reason it is unrealistic to expect successive tests to give exactly the same result and there is usually little purpose served by carrying out repeat analyses. However, if retest or replicate results are outside specified ranges or tolerances, it is routine seed-testing practice to repeat the tests on further samples or replicates to obtain more reliable results.

\section{CONCLUSION}

The value of seed cannot be estimated from a cursory examination. Careful analysis by skilled analysts is required to determine its purity, the types of impurities present, the germinating capacity of the seed and other quality attributes such as health status and varietal purity.

With plant production being the cornerstone on which many of New Zealand's primary industries are based, the provision of seed of known high quality is as important now as it has been over the past 100 years. In addition, there is a significant export market in seeds, and this market can only be retained if seed offered for sale has been properly tested and shown to be of acceptable quality.

\section{REFERENCES}

Brown, K. R., 1977. N.Z. /l exp. Agric., 5: 143-6.

Cockayne. A. H.. 1913. N.Z. II Aaric.., 5: 481-8.

Delouche, J. C.;' Baskin, C. C., 1973. Seed Sci. \& Technol., 1: 427-52.

Foy, N. R.; Hyde, E. O. C., 1937. N.Z. /l Agric., 55: 2 19-24.

Hampton, J. G.; Scott, D. J., 1980. N.Z. /l agric. Res. 23: In press.

Heydecker, W.. 1969. Proc. Int. Seed Test. Ass., 34: 201-19.

International Seed Testing Association (ISTA), 1976. Seed Sri. \& Technol, 4: 1-180.

Lancashire, J. A.; Hampton, J. G.; Gomez, J. S., 1980. In Herbage Seed Production. Grassld Res. and Pract, Ser. No. 1. New Zealand Grassland Association.

Lonsdale, T. W.. 1911. N.z. /l Agric., 2: 200-2.

McKenzie, E. H. C., 1978. N.z. Il Agric. Res., 21: 283-6.

Matthews, Dawn, 1971. Ibid.. 14: 219-26.

Perry, D. A., 1972. Hort. Abstr., 42: 334-42.

Scott, D. J., 1974. N.Z. Jl Agric., 129: 19. 